\title{
Türk popülasyonunda obstrüktif uyku apne sendromunda rol oynayan antropometrik ölçümlerin belirlenmesi
}

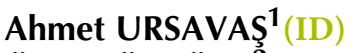
Önder ÖZTÜRK ${ }^{2}$ Oğuz KÖKTÜRK ${ }^{k}(\bar{I}=\overline{\overline{1}}$ Pinar MUTLU ${ }^{4}$ (ID)! Hatice KILIÇ ${ }^{5}(I D) !$ Aygül GÜZEL ${ }^{6}(\mathrm{ID})$ : Özge AYDIN GŨÇLÜ1!(ID)! Fatma ERBOY ${ }^{T_{1}}(\mathrm{ID}) \mathrm{C}$ - - , Emine ARGÜDE $\left.\overline{\mathbf{R}}^{5}(\mathrm{LI})\right)^{\prime}$ Habibe HEZER ${ }^{5}$ (ID)! Ebru Şengül ŞEREF PARLAK $^{5}($ ID $)$ :
\end{abstract}

A. Cemal PÁzARLI ${ }^{8}(I \Omega) !$ Sibel ÖZKURT 9 Neşe DURSUNÖĞLU Nurgül SEVIMLi ${ }^{3}$ (ID) Asiye KANBAY ${ }^{10}$ Ümit TUTAR ${ }^{11}$ Selma YEŞiLKAYYA ${ }^{71}$ Nevra Güllü ARSLAN ${ }^{11}$ Şerife SAVAS BOZBAŞ ${ }^{12}$ Elif KÜPELi12i(ID)!

Merve PINAR

Hilal ERMIŞ ${ }^{13}$

Çiğdem ÖZZDíLEKKCAN ${ }^{14}$ Nurhan SARIOĞLU ${ }^{15}$ Gülgün ÇETINTAŞ

AVSSAR $^{16}$

Adnan Kazım USALAN ${ }^{17}$ Sema SARAÇ ${ }^{16} 6_{(I D)}$ Aydanur EKICi ${ }^{1+8}$ Başak BURGAZLİŌĞLU ${ }^{19}$

CTelif Hakkı 2019 Tüberküloz ve Toraks. Makale metnine www.tuberktoraks.org web adresinden ulaşılabilir.
1 Uludağ Üniversitesi Tıp Fakültesi, Göğüs Hastalıkları Anabilim Dalı, Bursa, Türkiye

${ }^{1}$ Department of Chest Diseases, Faculty of Medicine, Uludag University, Bursa, Turkey

${ }^{2}$ Süleyman Demirel Üniversitesi Tıp Fakültesi, Göğüs Hastalıkları Anabilim Dalı, Isparta, Türkiye

2 Department of Chest Diseases, Faculty of Medicine, Suleyman Demirel University, Isparta, Turkey

${ }^{3}$ Gazi Üniversitesi Tıp Fakültesi, Göğüs Hastalıkları Anabilim Dalı, Ankara, Türkiye

${ }^{3}$ Department of Chest Diseases, Faculty of Medicine, Gazi University, Ankara, Turkey

${ }^{4}$ Çanakkale Onsekiz Mart Üniversitesi Tıp Fakültesi, Göğüs Hastalıkları Ánabilim Dalı, Çanakkale, Türkiye

${ }^{4}$ Department of Chest Diseases, Faculty of Medicine, Canakkale Onsekiz Mart University, Canakkale, Turkey

${ }^{5}$ Yıldırım Beyazıt Üniversitesi Tıp Fakültesi, Göğüs Hastalıkları Anabilim Dalı, Ankara, Türkiye

${ }^{5}$ Department of Chest Diseases, Faculty of Medicine, Yildirim Beyazit University, Ankara, Turkey

${ }^{6}$ Ondokuz Mayıs Üniversitesi Tıp Fakültesi, Gögüs Hastalıkları Anabilim Dalı, Samsun, Türkiye

${ }^{6}$ Department of Chest Diseases, Faculty of Medicine, Ondokuz Mayis University, Samsun, Turkey

${ }^{7}$ Zonguldak Bülent Ecevit Üniversitesi Tıp Fakültesi, Göğüs Hastalıkları Anabilim Dalı, Zonguldak, Türkiye

7 Department of Chest Diseases, Faculty of Medicine, Zonguldak Bulent Ecevit University, Zonguldak, Turkey

${ }^{8}$ Kahramanmaraş Elbistan Devlet Hastanesi, Göğüs Hastalıkları Kliniği, Kahramanmaraş, Elbistan, Türkiye

${ }^{8}$ Clinic of Chest Diseases, Kahramanmaras Elbistan State Hospital, Kahramanmaras, Elbistan, Turkey

${ }^{9}$ Pamukkale Üniversitesi Tıp Fakültesi, Göğüs Hastalıkları Anabilim Dalı, Denizli, Türkiye

${ }^{9}$ Department of Chest Diseases, Faculty of Medicine, Pamukkale University, Denizli, Turkey

10 i̇stanbul Medipol Üniversitesi Tıp Fakültesi, Göğüs Hastalıkları Anabilim Dalı, İstanbul, Türkiye

${ }^{10}$ Department of Chest Diseases, Faculty of Medicine, Istanbul Medipol University, Istanbul, Turkey 
Makale atıfı: Ursavaş A, Öztürk Ö, Köktürk O, Mutlu P, Kılıç $H$, Güzel $A$ ve ark. Türk popülasyonunda obstrüktif uyku apne sendromunda rol oynayan antropometrik ölçümlerin belirlenmesi. Tuberk Toraks 2019;67(4):24857.

Yazışma Adresi (Address for Correspondence)

\section{Dr. Pınar MUTLU}

Çanakkale Onsekiz Mart Üniversitesi

Tıp Fakültesi, Araştırma ve Uygulama Hastanesi, Göğüs Hastalıkları Anabilim Dalı,

ÇANAKKALE - TÜRKIYE

e-mail: pinarmutlu78@yahoo.com
11 Samsun Göğüs Hastalıkları ve Göğüs Cerrahisi Eğitim ve Araştırma Hastanesi, Göğüs Hastalıkları Kliniği, Samsun, Türkiye

${ }^{11}$ Clinic of Chest Diseases, Samsun Chest Diseases and Chest Surgery Training and Research Hospital, Samsun, Turkey

12 Başkent Üniversitesi Tıp Fakültesi, Göğüs Hastalıkları Anabilim Dalı, Ankara, Türkiye

12 Department of Chest Diseases, Faculty of Medicine, Baskent University, Ankara, Turkey

13 İnönü Üniversitesi Tıp Fakültesi, Göğüs Hastalıkları Anabilim Dalı, Malatya, Türkiye

${ }^{13}$ Department of Chest Diseases, Faculty of Medicine, Inonu University, Malatya, Turkey

${ }^{14}$ Ankara Dr. Abdurrahman Yurtaslan Onkoloji Eğitim ve Araştırma Hastanesi, Gögüus Hastalıkları Kliniği, Ankara, Türkiye

${ }^{14}$ Clinic of Chest Diseases, Ankara Dr. Abdurrahman Yurtaslan Oncology Training and Research Hospital, Ankara, Turkey

15 Balıkesir Üniversitesi Tıp Fakültesi, Göğüs Hastalıkları Anabilim Dalı, Balıkesir, Türkiye

15 Department of Chest Diseases, Faculty of Medicine, Balikesir University, Balikesir, Turkey

16 İstanbul Süreyyapaşa Gögüs Hastalıkları ve Göğüs Cerrahisi Eğitim ve Araştırma Hastanesi, Göğüs Hastalıkları Kliniği, İstanbul, Türkiye

${ }^{16}$ Clinic of Chest Diseases, Istanbul Sureyyapasa Chest Diseases and Chest Surgery Training and Research Hospital, Istanbul, Turkey

17 Tarsus Medical Park Hastanesi, Göğüs Hastalıkları Kliniği, Mersin, Tarsus, Türkiye

17 Clinic of Chest Diseases, Tarsus Medical Park Hospital, Mersin, Tarsus, Turkey

18 Kırıkkale Üniversitesi Tıp Fakültesi, Göğüs Hastalıkları Anabilim Dalı, Kırıkkale, Türkiye

18 Department of Chest Diseases, Faculty of Medicine, Kirikkale University, Kirikkale, Turkey

${ }^{19}$ Bursa Medical Park Hastanesi, Göğüs Hastalıkları Kliniği, Bursa, Türkiye

${ }^{19}$ Clinic of Chest Diseases, Bursa Medical Park Hospital, Bursa, Turkey

\section{ÖZ}

\section{Türk popülasyonunda obstrüktif uyku apne sendromunda rol oynayan antropometrik ölçümlerin belirlenmesi}

Giriş: Bu çalışmada, obstrüktif uyku apne sendromu (OSAS)'nun değerlendirilmesinde kullanılan antropometrik ölçüm ve oranların ülkemize ait değerlerini belirlemek istedik.

Materyal ve Metod: Çok merkezli prospektif olarak planlanan çalışmamıza 13 ilimizde yer alan, akredite olmuş 20 uyku merkezi katıldı. OSAS semptomları olan ve polisomnografik inceleme ile apne-hipopne indeksi (AHI) $\geq 5$ bulunan olgular OSAS çalışma grubu; AHI < 5 ve STOP-Bang < 2 olan olgular ise kontrol grubu olarak alındı. Olgulara ait demografik özellikler lyaş, cinsiyet, beden kitle indeksi (BKi)] ve antropometrik ölçümler (boyun, bel ve kalça çevresi, bel/kalça oranları) kaydedildi.

Bulgular: Çalışmaya 20 merkezden yaş ortalaması $50.50 \pm 0.21$ yıl olan 2684 (\%81.3'ü OSAS'ı) olgu alındı. Olgular, ülkemizin altı coğrafi bölgesinden (Akdeniz, Doğu Anadolu, Ege, liç Anadolu, Karadeniz ve Marmara Bölgesi) alındı. Olguların demografik özellikleri ve antropometrik ölçümleri; kontrol grubuna göre karşılaştırıldığında yaş, boyun, bel, kalça çevresi ve bel/kalça oranları ve BKi özellikleri; bölgelere göre karşılaştırıldığında ise yaş, boyun, bel, kalça çevresi ve bel/kalça oranları istatistiksel olarak farklı bulundu (sırasıyla $p<0.001, p<0.001, p<0.05)$. Cinsiyetlere göre karşılaştırıldığında yaş, boyun ve kalça çevresi, bel/kalça oranı, boy, kilo ve BKi özellikleri istatistiksel olarak farklı idi (sırasılla, $p<0.001$ ). Boyun çevresi ve bel/kalça oranı sırasılyla erkeklerde $42.58 \pm 0.10 \mathrm{~cm}$ (cut-off 41; duyarlılık \%61.2; özgüllük \%68.3), $0.99 \pm 0.002$ (cut-off 0.97; duyarlılı \%56.4; özgüllük \%54.3); kadınlarda $39.24 \pm$ $0.16 \mathrm{~cm}$ (cut-off 37; duyarlıık \%66.5; özgüllük \%63.4), $0.93 \pm 0.004$ (cut-off 0.89; duyarlılık \% 70.9; özgüllük \% 49.5) bulundu. OSAS fenotipleri; klasik OSAS, okült OSAS, REM bağımlı OSAS, pozisyon bağımlı OSAS, REM ve pozisyon bağımlı OSAS, overlap sendromu ve kompleks uyku apne sendromu olarak belirtildi. OSAS fenotiplerine göre karşılaştırıldığında yaş, boyun ve kalça çevresi, boy, kilo ve BKi özellikleri istatistiksel olarak farklı iken (sırasıyla, $p<0.001$ ) bel/kalça oranı farklı bulunmadı.

Sonuç: Boyun çevresi erkeklerde standart değerin altında iken, kadınlarda üstünde bulundu. Bel/kalça oranı hem erkeklerde hem de kadınlarda ideal ölçülerin üzerinde idi. Bu bağlamda ülke değerlerinin tespiti OSAS olasılığı olan hastaların belirlenmesini ve polisomnografi için uyku merkezlerine yönlendirilmesini sağlayacaktır.

Anahtar kelimeler: Obstrüktif uyku apne sendromu; cinsiyet; boyun çevresi; bel çevresi; bel/kalça oranı; antropometrik özellikler 


\begin{abstract}
Determination of anthropometric measurements in obstructive sleep apnea syndrome in Turkish population

Introduction: In this study, we aimed to determine the values of anthropometric measurements and rates used in the evaluation of obstructive sleep apnea syndrome (OSAS) in our country.

Materials and Methods: Twenty accredited sleep centers in thirteen provinces participated in this multicenter prospective study. OSAS symptoms and polysomnographic examination and apnea-hypopnea index (AHI) $\geq 5$ cases OSAS study group; patients with $A H I<5$ and STOP-Bang $<2$ were included as control group. Demographic characteristics (age, sex, body mass index-BMI) and anthropometric measurements (neck, waist and hip circumference, waist/hip ratio) of the subjects were recorded.

Results: The study included 2684 patients (81.3\% OSAS) with a mean age of $50.50 \pm 0.21$ years from 20 centers. The cases were taken from six geographical regions of the country (Mediterranean, Eastern Anatolia, Aegean, Central Anatolia, Black Sea and Marmara Region). Demographic characteristics and anthropometric measurements; age, neck, waist, hip circumference and waist/ hip ratios and BMI characteristics when compared with the control group; when compared according to regions, age, neck, waist, hip circumference and waist/hip ratios were found to be statistically different $(p<0.001, p<0.001, p<0.05$, respectively). When compared by sex, age, neck and hip circumference, waist/hip ratio, height, weight and BMI characteristics were statistically different $(p<0.001$, respectively). Neck circumference and waist/hip ratio were respectively $42.58 \pm 0.10 \mathrm{~cm}, 0.99 \pm 0.002,39.24 \pm 0.16$ $\mathrm{cm}, 0.93 \pm 0.004$ were found in women.
\end{abstract}

Conclusion: The neck circumference was lower than the standard value in men, but higher in women. The waist/hip ratio was above the ideal measurements in both men and women. In this context, the determination of the country values will allow the identification of patients with the possibility of OSAS and referral to sleep centers for polysomnography.

Key words: OSAS; gender; neck circumference; waist circumference; waist/hip ratio

\section{GíRiş}

Obstrüktif uyku apne sendromu (OSAS), uyku sırasında tekrarlayan üst solunum yolu obstrüksiyonları ile karakterize, uyku bölünmeleri, gündüz aşırı uykululuk ve bilişsel bozulma gibi semptomlara yol açan yaygın bir hastalıktır. OSAS tanısı, klinik semptomların ve gece boyunca kaydedilen polisomnografi (PSG) bulgularının bir kombinasyonudur (1).

OSAS, metabolik sendrom, tip 2 diabetes mellitus ve kardiyovasküler hastalıklar ile (hipertansiyon, atriyal fibrilasyon, miyokart infarktüsü ve kalp yetmezliği gibi) birlikte ortaya çıkabilir (2-7). Hatta uzun süre tedavi edilmeyen hafif OSAS bile, ciddi kardiyovasküler komplikasyonlara neden olabilir (8). Toplum temelli çalışmalar, orta ve ağır OSAS olan hastalarda mortalitenin arttığını göstermiştir $(9,10)$. OSAS hastaIarının erken saptanması, ciddi morbidite ve mortalite gelişimini önleyebileceği için, temel bir halk sağlığı önceliği olmalıdır.

PSG, OSAS tanısı için altın standart olmasına rağmen, pahalı bir yöntemdir, yoğun emek gerektirir ve her hasta için ulaşılabilir değildir. Bu yüzden, günümüzde, özellikle batı popülasyonlarında, OSAS ile korele olabilecek antropometrik ölçümler araştırılmaktadır (11-14).

Antropometrik değişkenlerin, etnik değişkenlik ve yaşam tarzı alışkanlıklarına doğrudan bağlı olduğu bilinmektedir (15). Bu yüzden, Batı toplumlarından hem etnik hem de yaşam tarzı olarak farklı olan ülkelerin yaptığı OSAS ile ilişkili antropometrik ölçüm çalışmalarına ihtiyaç vardır.

Çalışmamızın amacı, OSAS tanısında kullanılan antropometrik ölçüm ve oranların ülkemize ait değerlerini belirlemektir. Büyük bir hasta grubundaki çeşitli antropometrik ve obezite dağılım indekslerini, cinsiyetin etkisini hesaba katarak araşıırdık. OSAS için yüksek risk altındaki hastaları tanımlayabilecek sınır değerlerini bulmaya amaçladık.

\section{MATERYAL ve METOD}

$\mathrm{Bu}$ çalışma, Süleyman Demirel Üniversitesi Tıp Fakültesi Hastanesinin Etik Kurulu tarafından onaylandı (onay numarası: 217). Tüm katılımcılar yazılı onay verdi. Çalışmamız Helsinki Bildirgesine uygundur.

\section{Çalışma Tasarımı}

Çok merkezli, prospektif olarak planlanan çalışmamıza 13 şehrimizde yer alan, akredite olmuş 20 uyku laboratuvarı katıldı. Çalışmaya 18 yaş üstü hastalar dahil edildi. OSAS semptomları olan ve polisomnografik inceleme ile apne-hipopne indeksi $(\mathrm{AHI}) \geq 5$ bulunan olgular OSAS çalışma grubu; AHI $<5$ ve STOP-Bang $<2$ olan olgular ise kontrol grubu olarak alındı. Çalışmaya alınan toplam 2684 olgunun, 2182 (\%81.3)'si OSAS'lı idi. Olgulara ait demografik özellikler [yaş, cinsiyet, beden kitle indeksi (BKi)] ve antropometrik ölçümler (boyun, bel ve kalça çevresi, $\mathrm{bel} / \mathrm{kalça}$ oranları) kaydedildi. 
Tüm hastalara gece boyu PSG yapıldı. İşlem, elektroensefalografi, elektrookülografi, elektrokardiyografi ve elektromiyografi için yüzey elektrotlarından ve nazaloral hava akımı için termistör ve burun basıncı transdüserinden, trakeal sesler, torasik ve abdominal solunumdan alınan kayıtlardan oluşmaktadır. Oksijen satürasyonunun izlenmesi, bir parmak nabız oksimetresi ile sürekli olarak gerçekleştirildi. Uyku sırasındaki yatış pozisyonu değişiklikleri kaydedildi ve tüm gece video kayıtları da test süresince yapıldı. Veriler bilgisayarlı bir polisomnografik sistemde toplandı ve skorlama işlemi manuel olarak yapıldı. Uyku ve solunum olayları, Amerikan Uyku Tıbbı Akademisinin kriterlerine göre skorlandı (16). Apne, en az $10 \mathrm{~s}$ süren hava akımının kesilmesi olarak tanımlandı. Hipopne, nazal basınç transdüseri tarafından ölçülen $10 \mathrm{~s}$ veya daha fazla süren, hava akımında \%30 veya daha fazla düşüşe oksijen satürasyonunda \%4 veya daha fazla bir düşüşün eşlik etmesi veya hava akımında \%50 veya daha fazla düşüşe oksijen satürasyonunda \%3 veya daha fazla bir düşüşün eşlik etmesi olarak tanımlandı. Uyanayazmalar (arousallar), değişiklikten önce en az 10 saniye sabit uyku olması şartıyla, EEG aktivitesinde en az 3 saniye frekansda bir değişiklik olmasıydı. AHI uykuda saatte meydana gelen apne ve hipopne olaylarının sayısı olarak tanımlandı.

AHi değeri 5'e eşit veya daha büyük olan hastalar OSAS olarak teşhis edildi.

Aşağıdaki antropometrik değişkenlerin ölçümleri, PSG gecesi kalifiye bir uyku teknisyeni tarafından yapıldı: boy, kilo, boyun, bel ve kalça; BKi'nin ve belkalça oranları, yukarıdaki ölçümlerden hesaplandı.

Vücut ağırlığı; hafif, yatmadan önce giyinen ve ayakkabı olmadan ayakta dururken, kilogram olarak kaydedildi.

BKi, vücut ağırlığı $(\mathrm{kg}) / \mathrm{boy}^{2}\left(\mathrm{~m}^{2}\right)$ olarak hesaplandı.

Boyun çevresi, krikotiroid membran düzeyinde santimetre $(\mathrm{cm})$ cinsinden ölçüldü.

Bel çevresi, alt kaburga kenarı ile ön süperior iliyak omurgası arasından $\mathrm{cm}$ cinsinden ölçüldü.

Kalça çevresi $(\mathrm{cm})$, hasta ayakta dururken kalçaların maksimum çevresinden ölçüldü.

Tüm uyku teknisyenleri, ölçümlerin gözlemciler arası güvenilirliğini sağlamak için, bu ölçümleri alma konusunda eğitildi.

\section{Anketler}

Tüm olgulara STOP-Bang ve Epworth Uykululuk Skalası (EUS) anketleri uygulandı.

STOP-Bang anketi 8 maddelik bir ankettir ve her madde 1 puan olarak hesaplandı. Daha yüksek puan alan hastalarda OSAS olasılığının daha yüksek olduğunu göstermektedir (17).

STOP-Bang anketi Türkçe olarak doğrulandı (18).

Gündüz aşırı uykululuk hali EUS ile ölçüldü. EUS, sekiz sorudan oluşan, basit ve güvenilir bir ankettir. Her soru 0-3 puan alır ve yüksek puanlara sahip olmak, gündüz aşırı uykululuk halinin fazla olduğunu gösterir. EUS Türkçe olarak doğrulandı (19).

\section{İstatistiksel Analiz}

Elde edilen veriler SPSS 22.0 istatistik paket programında değerlendirildi.

Welch t testi ve Wilcoxon-Mann-Whitney testi, OSAS ve sağlıklı bireyler arasında, bel-boy oranı, bel çevresi ve BKi açısından bir fark olup olmadığını belirlemek için kullanıldı.

Normal dağılıma sahip veriler ortalama \pm standart sapma olarak ifade edildi. Normal olmayan veriler için medyan, minimum ve maksimum değerleri verildi.

OSAS riski yüksek olan hastaları tespit etmek için eşik değerlerini hesaplamada ROC analizi kullanıldı. Tüm analizler kadınlar ve erkekler için ayrı ayrı tekrarlandı. $p<0.05$ değeri istatistiksel olarak anlamlı kabul edildi.

\section{BULGULAR}

Çalışmaya 20 merkezden yaş ortalaması $50.50 \pm$ 0.21 yıl olan 2684 olgu alınmıştır. Çalışmaya alınan olgulardan 2182 (\%81.3'ü)'si OSAS'lı idi. Olguların antropometrik ve polisomnografik özellikleri Tablo 1 'de verilmiştir.

Olguların demografik özellikleri ve antropometrik ölçümleri; cinsiyetlere göre karşılaştırıldığında yaş, boyun ve kalça çevresi, bel/kalça oranı, boy, kilo ve BKi özellikleri istatistiksel olarak farklı idi $(p<0.001)$ (Tablo 2).

Boyun çevresi; erkeklerde $42.58 \pm 0.10 \mathrm{~cm}$ (cut-off 41; duyarlılık \%61.2; özgüllük \%68.3), kadınlarda $39.24 \pm 0.16$ cm (cut-off 37; duyarlılık \%66.5; özgüllük \%63.4) bulunmuştur. 
Türk popülasyonunda OSAS'da rol oynayan antropometrik ölçümler

Tablo 1. Antropometrik ve polisomnografik bulguların gruplara göre dağılım

\begin{tabular}{|lccc|} 
& $\begin{array}{c}\text { Grup 1 } \\
\text { OSAS (n= 2182) }\end{array}$ & $\begin{array}{c}\text { Grup 2 } \\
\text { Kontrol (n= 502) }\end{array}$ & p \\
\hline Cinsiyet (erkek/kadın) & $1562 / 620$ & $300 / 202$ & $0.000^{\mathrm{a}}$ \\
Yaş (yıl) & $51.40 \pm 0.23$ & $46.63 \pm 0.50$ & $0.000^{\mathrm{b}}$ \\
Boy $(\mathrm{cm})$ & $168.85 \pm 0.21$ & $167.36 \pm 0.41$ & $0.02^{\mathrm{b}}$ \\
Kilo $(\mathrm{kg})$ & $91.93 \pm 0.36$ & $81.89 \pm 0.67$ & $0.000^{\mathrm{b}}$ \\
BKi $\left(\mathrm{kg} / \mathrm{m}^{2}\right)$ & $32.71 \pm 0.26$ & $29.20 \pm 0.25$ & $0.000^{\mathrm{b}}$ \\
Boyun çevresi $(\mathrm{cm})$ & $41.63 \pm 0.09$ & $38.75 \pm 0.17$ & $0.000^{\mathrm{b}}$ \\
Bel çevresi $(\mathrm{cm})$ & $110.02 \pm 0.28$ & $101.32 \pm 0.54$ & $0.000^{\mathrm{b}}$ \\
Kalça çevresi $(\mathrm{cm})$ & $112.80 \pm 0.26$ & $106.88 \pm 0.50$ & $0.000^{\mathrm{b}}$ \\
Bel/kalça oranı & $0.97 \pm 0.001$ & $0.94 \pm 0.004$ & $0.000^{\mathrm{a}}$ \\
STOP-Bang & $4.72 \pm 0.04$ & $3.20 \pm 0.07$ & $0.000^{\mathrm{b}}$ \\
Epworth & $9.10 \pm 0.12$ & $6.77 \pm 0.24$ & $0.000^{\mathrm{a}}$ \\
AHi & $35.80 \pm 0.60$ & $2.21 \pm 0.11$ & $0.000^{\mathrm{a}}$ \\
\hline a: Kruskal Wallis, b: Oneway anova (ortalama \pm standart hata, $\mathrm{p}<0.05)$. & & \\
\hline
\end{tabular}

Tablo 2. Antropometrik ve polisomnografik bulguların cinsiyetlere göre dağılımı

\begin{tabular}{|c|c|c|c|c|c|}
\hline & \multicolumn{2}{|c|}{ Erkek } & \multicolumn{2}{|c|}{ Kadın } & \multirow[b]{2}{*}{$\mathbf{p}$} \\
\hline & OSAS $(n=1562)$ & Kontrol $(n=300)$ & OSAS $(n=620)$ & Kontrol $(n=202)$ & \\
\hline Yaş (yıl) & $49.79 \pm 0.27$ & $45.84 \pm 0.70$ & $55.43 \pm 0.39$ & $47.80 \pm 0.69$ & $0.000^{\mathrm{a}}$ \\
\hline Boy $(\mathrm{cm})$ & $172.69 \pm 0.18$ & $172.42 \pm 0.40$ & $159.18 \pm 0.30$ & $159.84 \pm 0.46$ & $0.000^{\mathrm{a}}$ \\
\hline Kilo (kg) & $93.48 \pm 0.41$ & $85.11 \pm 0.78$ & $88.03 \pm 0.71$ & $77.12 \pm 1.11$ & $0.000^{\mathrm{a}}$ \\
\hline BKi $\left(\mathrm{kg} / \mathrm{m}^{2}\right)$ & $31.39 \pm 0.13$ & $28.49 \pm 0.25$ & $36.02 \pm 0.84$ & $30.19 \pm 0.48$ & $0.000^{\mathrm{a}}$ \\
\hline Boyun çevresi $(\mathrm{cm})$ & $42.58 \pm 0.10$ & $40.20 \pm 0.20$ & $39.24 \pm 0.16$ & $36.60 \pm 0.26$ & $0.000^{\mathrm{a}}$ \\
\hline Bel çevresi $(\mathrm{cm})$ & $109.60 \pm 0.32$ & $102.35 \pm 0.62$ & $111.09 \pm 0.59$ & $99.79 \pm 0.98$ & $0.542^{b}$ \\
\hline Kalça çevresi $(\mathrm{cm})$ & $110.41 \pm 0.26$ & $104.38 \pm 0.52$ & $118.84 \pm 0.58$ & $110.60 \pm 0.93$ & $0.000^{\mathrm{a}}$ \\
\hline $\mathrm{Bel} / \mathrm{kalça}$ oranı & $0.99 \pm 0.002$ & $0.98 \pm 0.004$ & $0.93 \pm 0.004$ & $0.90 \pm 0.006$ & $0.000^{\mathrm{a}}$ \\
\hline STOP-Bang & $4.85 \pm 0.04$ & $3.59 \pm 0.09$ & $4.40 \pm 0.07$ & $2.61 \pm 0.11$ & $0.000^{\mathrm{a}}$ \\
\hline Epworth & $9.04 \pm 0.14$ & $6.67 \pm 0.30$ & $9.25 \pm 0.23$ & $6.93 \pm 0.39$ & $0.805^{b}$ \\
\hline $\mathrm{AHI}$ & $36.14 \pm 0.71$ & $2.27 \pm 0.11$ & $34.95 \pm 1.13$ & $2.14 \pm 0.20$ & $0.001^{b}$ \\
\hline
\end{tabular}

Bel/kalça oranı; erkeklerde $0.99 \pm 0.002$ (cut-off 0.97; duyarlılık \%56.4; özgüllük \%54.3), kadınlarda $0.93 \pm 0.004$ (cut-off 0.89; duyarlılık \%70.9; özgüllük \%49.5) bulunmuştur.

Olgular, ülkemizin altı coğrafi bölgesinden (Akdeniz, Doğu Anadolu, Ege, İç Anadolu, Karadeniz ve Marmara Bölgesi) alınmıştır. Olguların demografik özellikleri ve antropometrik ölçümleri; bölgelere göre karşılaştırıldığında yaş, boyun, bel, kalça çevresi ve bel/kalça oranları istatistiksel olarak farklı bulunmuştur (sırasıyla; $\mathrm{p}<0.001, \mathrm{p}<0.001, \mathrm{p}<0.05$ ) (Tablo 3).

OSAS fenotipleri; klasik OSAS, okült OSAS, REM bağımlı OSAS, pozisyon bağımlı OSAS, REM ve pozisyon bağımlı OSAS, overlap sendromu ve kompleks uyku apne sendromu olarak belirtilmiştir. OSAS fenotiplerine göre karşılaştırıldığında yaş, boyun ve kalça çevresi, boy, kilo ve BKi özellikleri istatistiksel olarak farklı iken $(p<0.001)$ bel/kalça oranı farklı bulunmamıştır (Tablo 4). 


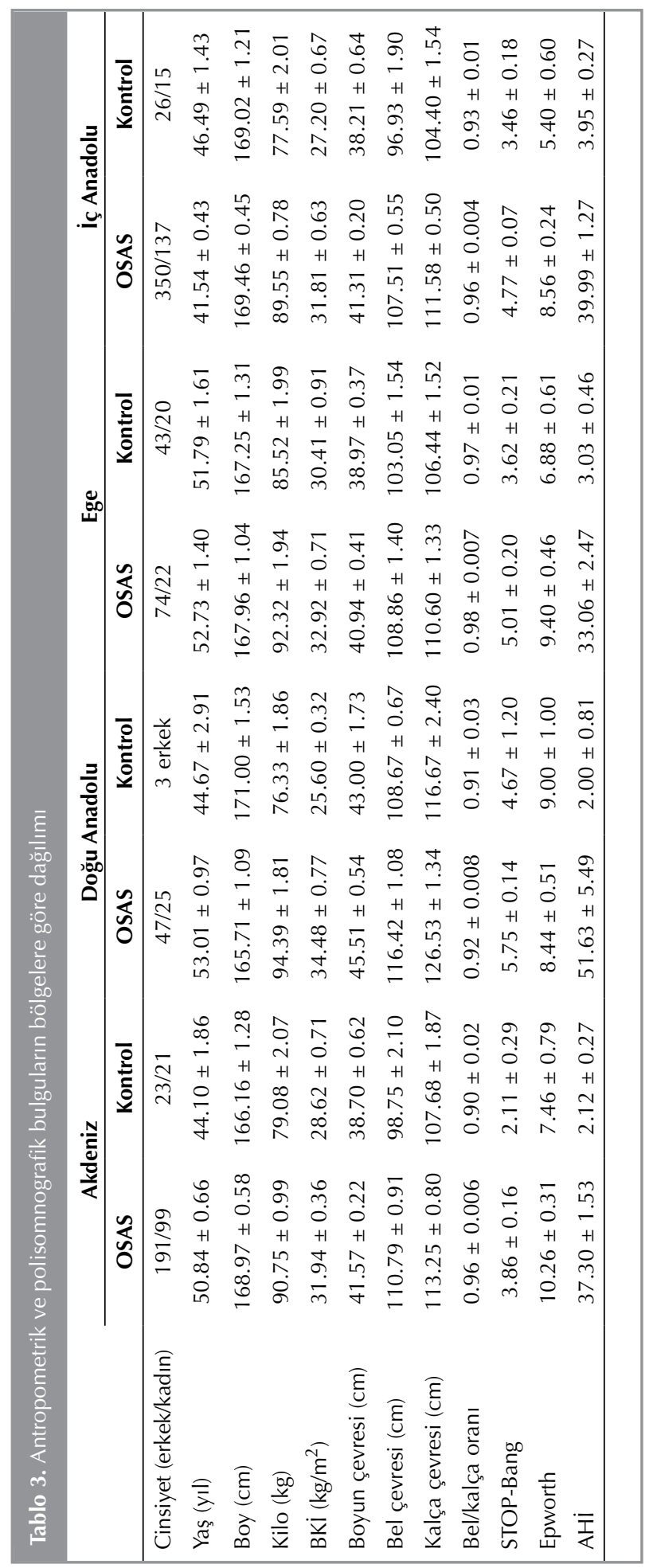


Türk popülasyonunda OSAS'da rol oynayan antropometrik ölçümler

Tablo 3. Antropometrik ve polisomnografik bulguların bölgelere göre dağılımı (devamı)

\begin{tabular}{|c|c|c|c|c|}
\hline & \multicolumn{2}{|c|}{ Karadeniz } & \multicolumn{2}{|c|}{ Marmara } \\
\hline & OSAS & Kontrol & OSAS & Kontrol \\
\hline Cinsiyet (erkek/kadın) & $464 / 168$ & $145 / 103$ & $436 / 169$ & $60 / 43$ \\
\hline Yaş (yıl) & $51.75 \pm 0.45$ & $45.94 \pm 0.70$ & $50.76 \pm 0.44$ & $46.33 \pm 1.08$ \\
\hline Boy $(\mathrm{cm})$ & $168.53 \pm 0.38$ & $167.36 \pm 0.58$ & $169.16 \pm 0.30$ & $167.15 \pm 0.94$ \\
\hline Kilo $(\mathrm{kg})$ & $93.67 \pm 0.72$ & $82.63 \pm 0.97$ & $92.25 \pm 0.65$ & $80.98 \pm 1.47$ \\
\hline BKi $\left(\mathrm{kg} / \mathrm{m}^{2}\right)$ & $33.22 \pm 0.27$ & $29.39 \pm 0.34$ & $33.00 \pm 0.70$ & $29.03 \pm 0.52$ \\
\hline Boyun çevresi $(\mathrm{cm})$ & $41.67 \pm 0.16$ & $38.74 \pm 0.24$ & $41.54 \pm 0.16$ & $38.73 \pm 0.43$ \\
\hline Bel çevresi $(\mathrm{cm})$ & $112.48 \pm 0.52$ & $102.64 \pm 0.76$ & $108.54 \pm 0.50$ & $99.64 \pm 1.13$ \\
\hline Kalça çevresi $(\mathrm{cm})$ & $113.67 \pm 0.49$ & $107.74 \pm 0.71$ & $111.39 \pm 0.46$ & $105.42 \pm 1.11$ \\
\hline $\mathrm{Bel} /$ kalça oranı & $0.98 \pm 0.003$ & $0.95 \pm 0.005$ & $0.97 \pm 0.004$ & $0.94 \pm 0.01$ \\
\hline STOP-Bang & $4.58 \pm 0.06$ & $3.01 \pm 0.11$ & $4.98 \pm 0.006$ & $3.66 \pm 0.14$ \\
\hline Epworth & $8.40 \pm 0.22$ & $5.70 \pm 0.32$ & $9.75 \pm 0.24$ & $8.95 \pm 0.57$ \\
\hline AHI & $31.37 \pm 1.14$ & $1.59 \pm 0.10$ & $34.90 \pm 1.00$ & $2.58 \pm 0.28$ \\
\hline
\end{tabular}

Tablo 4. Antropometrik ve polisomnografik bulguların OSAS fenotiplerine göre dağılımı

\begin{tabular}{|c|c|c|c|c|c|c|c|}
\hline & $\begin{array}{c}\text { Klasik OSAS } \\
(n=1629)\end{array}$ & $\begin{array}{c}\text { Okült OSAS } \\
(\mathbf{n}=15)\end{array}$ & $\begin{array}{l}\text { REM bağımlı } \\
\text { OSAS } \\
(n=106)\end{array}$ & $\begin{array}{c}\text { Pozisyon } \\
\text { bağımlı OSAS } \\
(n=311)\end{array}$ & $\begin{array}{c}\text { REM ve } \\
\text { pozisyon } \\
\text { bağımlı OSAS } \\
(n=45)\end{array}$ & $\begin{array}{c}\text { Overlap } \\
\text { sendromu } \\
(n=71)\end{array}$ & $\begin{array}{c}\text { Kompleks } \\
\text { uyku apne } \\
\text { sendromu } \\
(n=5)\end{array}$ \\
\hline Cinsiyet (E/K) & $1167 / 462$ & $12 / 3$ & $54 / 52$ & $251 / 60$ & $31 / 14$ & $43 / 28$ & $4 / 1$ \\
\hline Yaş (yıl) & $51.40 \pm 0.27$ & $44.27 \pm 0.81$ & $51.20 \pm 0.96$ & $50.68 \pm 0.61$ & $48.91 \pm 1.66$ & $57.54 \pm 1.22$ & $55.00 \pm 3.86$ \\
\hline Boy $(\mathrm{cm})$ & $168.87 \pm 0.24$ & $171.47 \pm 1.78$ & $165.28 \pm 0.91$ & $170.70 \pm 0.57$ & $168.73 \pm 1.46$ & $165.37 \pm 1.19$ & $165.80 \pm 4.21$ \\
\hline Kilo (kg) & $93.03 \pm 0.24$ & $92.87 \pm 5.04$ & $90.92 \pm 1.79$ & $87.40 \pm 0.81$ & $84.56 \pm 2.06$ & $92.72 \pm 2.16$ & $89.80 \pm 5.45$ \\
\hline BKi $\left(\mathrm{kg} / \mathrm{m}^{2}\right)$ & $33.19 \pm 0.34$ & $31.88 \pm 2.09$ & $33.43 \pm 0.74$ & $30.05 \pm 0.29$ & $29.72 \pm 0.72$ & $34.27 \pm 0.91$ & $33.53 \pm 2.41$ \\
\hline $\begin{array}{l}\text { Boyun çevresi } \\
(\mathrm{cm})\end{array}$ & $41.94 \pm 0.10$ & $41.27 \pm 0.81$ & $40.03 \pm 0.39$ & $40.61 \pm 0.19$ & $39.43 \pm 0.57$ & $42.88 \pm 0.57$ & $41.40 \pm 1.78$ \\
\hline $\begin{array}{l}\text { Bel çevresi } \\
(\mathrm{cm})\end{array}$ & $110.73 \pm 0.32$ & $108.20 \pm 3.14$ & $110.15 \pm 1.51$ & $105.94 \pm 0.66$ & $104.13 \pm 1.57$ & $115.60 \pm 1.74$ & $110.40 \pm 5.95$ \\
\hline $\begin{array}{l}\text { Kalça çevresi } \\
(\mathrm{cm})\end{array}$ & $113.40 \pm 0.30$ & $105.93 \pm 7.43$ & $113.51 \pm 1.26$ & $109.40 \pm 0.57$ & $108.35 \pm 1.29$ & $117.24 \pm 1.67$ & $144.80 \pm 4.51$ \\
\hline $\begin{array}{l}\text { Bel/kalça } \\
\text { oranı }\end{array}$ & $0.97 \pm 0.002$ & $0.94 \pm 0.02$ & $0.97 \pm 0.01$ & $0.96 \pm 0.004$ & $0.96 \pm 0.01$ & $0.98 \pm 0.01$ & $0.96 \pm 0.02$ \\
\hline STOP-Bang & $4.80 \pm 0.04$ & $3.73 \pm 0.47$ & $4.42 \pm 0.16$ & $4.43 \pm 0.08$ & $3.62 \pm 0.24$ & $5.44 \pm 0.18$ & $5.40 \pm 0.68$ \\
\hline Epwort & $9.20 \pm 0.14$ & $8.80 \pm 1.45$ & $8.37 \pm 0.53$ & $8.57 \pm 0.34$ & $7.02 \pm 0.66$ & $11.35 \pm 0.70$ & $11.60 \pm 1.21$ \\
\hline $\mathrm{AHI}$ & $40.10 \pm 0.71$ & $19.63 \pm 5.98$ & $13.05 \pm 0.87$ & $23.77 \pm 1.24$ & $10.58 \pm 1.10$ & $42.93 \pm 3.18$ & $39.20 \pm 11.97$ \\
\hline
\end{tabular}

\section{TARTIŞMA}

Çalışmamızda, ülkemizde yetişkin popülasyonunda çeşitli antropometrik ölçümleri ve bunların OSAS'ın fenotipleriyle ilişkisini analiz ettik. Bildiğimiz kadarıyla, ülkemizde, altı coğrafi bölgelerden olgu alarak, boyun çevresi, kalça çevresi, bel çevresi, bel/kalça oranı ve BKI dahil olmak üzere antropometrik endekslerde OSAS riskini öngörmek için cut-off değerlerini belirleyen ilk çalışmadır.

Obezite, özellikle santral obezite, OSAS için önemli bir risk faktörüdür (20). Bel çevresi, BKi ve bel-kalça oranı gibi birçok basit antropometrik endeks, yaygın 
olarak obezite veya santral obezite belirteçleri olarak kullanılmaktadır. Bel veya kalça çevresindeki 13-15 cm'lik artış, OSAS riskini dört kat arttırmaktadır (1).

Bu antropometrik ölçümleri kullanan obezite kriterleri, cinsiyet ve etnik kökene göre farklıdır çünkü vücuttaki yağ dağılımı ve obezite şiddeti, genetik ve çevresel etkilerin karmaşık bir etkileşimine bağlıdır (21-23).

Son zamanlarda, boyun çevresi ve bel/kalça oranının, merkezi obezite endeksi ve OSAS'ın potansiyel bir öngörücüsü olarak, BKi'den daha iyi bir belirteç olduğu tanımlanmıştır. Deegan ve McNicholas, erkeklerde AHI ile bel çevresinin, boyun çevresinden daha yakından ilişkili olduğunu bildirmişlerdir (24). Subramanian ve arkadaşları, bel/boy oranının, erkeklerde OSAS'ın ciddiyeti ile ilişkili olduğunu ancak kadınlarda olmadığını göstermişlerdir (11). Onat ve arkadaşları, boyun çevresinin; bel çevresi gibi, metabolik sendromun bileşenlerine katkıda bulunduğunu bildirmiş̧lerdir (12).

Boyun çevresinin, OSAS için yüksek bir prediktif değeri olduğu bilinmektedir (25). Kalın boyunlular, üst solunum yollarının yumuşak dokusunda yă̆ birikmesine yatkındır, bu da üst solunum yolunun tıkanmasına neden olur ve OSAS ile sonuçlanır (26). Gene Cizza ve arkadaşları, 92 obez kadında yaptıkları çalışmada, $38 \mathrm{~cm}$ ve üzeri boyun çevresinin, OSAS'ın varlığını öngörmede, \%58 duyarlılığa ve \%79 özgüllüğe sahip olduğunu belirtmişlerdir (27).

Amerika Birleşik Devletleri'nde yapılan başka bir çalışmada, Davidson ve arkadaşları, boyun çevresinde erkeklerde $43 \mathrm{~cm}$ 'nin, kadınlarda ise $38 \mathrm{~cm}$ 'nin OSAS varlığını öngörmede etkili olduğunu söylemişlerdir (28).

Bizim çalışmamızda ise, OSAS riski için belirlenen, boyun çevresi cut-off değerleri erkeklerde $41 \mathrm{~cm}$, kadınlarda $37 \mathrm{~cm}$ 'di. Bu değerler, ilginç olarak, daha önce ülkemizde tek merkezde, Soylu ve arkadaşları tarafından yapılan çalışmadaki değerlerden yüksek ama diğer ülkelerde yapılan çalışmalarda bulunan cut-off değerlerine daha yakındır (13).

Bu sonuçların ışığında, boyun çevresinin, diğer antropometrik ölçümlere göre etnik köken farklılıklarından daha az etkilenen, OSAS için daha faydalı ve bağımsız bir öngörücü olduğunu düşünmekteyiz.

Genel olarak abdominal obezite, bel çevresinin, Asya popülasyonunda, erkeklerde $90 \mathrm{~cm}$ veya daha fazla, kadınlarda $80 \mathrm{~cm}$ veya daha fazla; Orta Doğu ve Kafkaslarda ise erkeklerde $94 \mathrm{~cm}$ veya daha fazla, kadınlarda $80 \mathrm{~cm}$ veya daha fazla olarak tanımlanmaktadır (29). Bizim çalışmamızda bulduğumuz, bel çevresi için cut-off değerleri, erkeklerde $109.6 \mathrm{~cm}$, kadınlarda $111 \mathrm{~cm}$ 'dir ve literatüre göre yüksektir. Aynı şiddette OSAS'a sahip olan, Asya'daki hastalar, Kafkas hastalara göre daha az obezdir, bu da etnik kökenin farklı şekilde OSAS'a katkıda bulunabileceğini göstermektedir (30).

Kafkas popülasyonunda obezite için BKI'nin cut-off değeri $30 \mathrm{~kg} / \mathrm{m}^{2}$ 'dir, fakat Asya popülasyonlarında obezite, daha düşük bir BKi'de, $25 \mathrm{~kg} / \mathrm{m}^{2}$ olarak yeniden tanımlanmıştır (31). Bizim çalışmamızda da, bir OSAS belirleyicisi olarak BKi için cut-off değerleri; kadınlarda $36.02 \mathrm{~kg} / \mathrm{m}^{2}$ 'nin üzerinde ve erkeklerde $31.39 \mathrm{~kg} / \mathrm{m}^{2 \prime}$ nin üzerindedir. Bulduğumuz bu değerler, literatürde belirtilen Kafkas popülasyonun değerlerine yakındır çünkü Asyalılar genellikle aynı yaş, cinsiyet ve BKI'deki Kafkas popülasyonuna göre daha yüksek vücut yağ yüzdesine sahiptir (32). Kafkas, Asya popülasyonlarının karşılaştırıldığı başka bir çalışmada; Lee ve arkadaşları OSAS'lı 150 erişkinde (74'ü Kafkas, 76'sı Çinli) kraniyofasiyal yapı ve obezite farklılığını değerlendirmişlerdir (28). Bu etnik araştırmada, Kafkas popülasyonuyla aynı derecede obeziteye sahip olan Çinli popülasyonda, daha şiddetli OSAS ve daha fazla kraniyofasiyal kemik patolojileri vardı. OSAS şiddeti benzer olduğunda ise, Kafkas hastalar daha yüksek bir BKi ve daha kalın bir boyun çevresine sahipken, Çinli hastalarda daha fazla kraniyofasiyal kemik patolojileri saptanmıştır. Bu nedenle, genetik veya kraniyofasiyal yapısal faktörler, obezitenin ötesinde OSAS riskine katkıda bulunabilir.

Çalışmamızda, OSAS prevalansında, belirgin bir cinsiyet farkı olduğunu bulduk. Erkek olgular, ortalama olarak daha genç, daha ağır ve daha kalın boyun çevresine sahipti. Özellikle, seks hormonu durumu kadınlarda OSAS için iyi bilinen bir risk faktörüdür (33). Bizim verilerimiz kadınların menopoz durumunu içermemesine rağmen, bu çalışmada kadınların ortalama yaşı (55 yaş) menopoz sonrası yaşlara çok yakındı.

Cinsiyetin, OSAS fenotipinin kilit yönlerini etkilediği iyi tespit edilmekle birlikte, vücut yağ dağılımı, üst solunum yolu kollapsitesi, hormonal durum ve ventilasyon kontrolü gibi çeşitli faktörlerin oynadığı rol, tam olarak açıklığa kavuşturulmamıştır (34-39).

Cinsiyet ile ilgili yapılan başka bir çalışmada, belkalça oranı erkeklerde $>1$, kadınlarda $>0.85$ ise 
OSAS görülme riskinin 2.6 kat daha yüksek olduğu bulunmuştur (40).

Literatürü incelediğimizde, OSAS fenotipleri ile antropometrik ve polisomnografik bulguların karşılaş̧ırıldığı bir çalışmayla karşılaşmadık. Çalışmamızda, klasik OSAS $(n=1629)$, okült OSAS $(n=15)$, REM bağımlı OSAS $(n=106)$, pozisyon bağımlı OSAS $(n=$ 311), REM ve pozisyon bağımlı OSAS $(n=45)$, Overlap sendromu $(n=71)$ ve kompleks uyku apne sendromu $(n=5)$ şeklinde fenotipleri değerlendirdik. OSAS fenotiplerine göre karşılaştırıldı̆̆ında yaş, boyun ve kalça çevresi, boy, kilo ve BKi özellikleri istatistiksel olarak farklı iken $(p<0.001)$ bel/kalça oranı farklı bulunmadı.

Fakat bu dağılım, olgu sayısı bakımından homojenite sağlamamaktadır. Bu alanda, her fenotipten yeterli olgu sayısına sahip çalışmaların, gelecekte planlanması gerektiğini düşünmekteyiz.

Çalışmamızın kısıtlılıkları; erkek hasta baskınlığı nedeniyle dengesiz bir cinsiyet dağııımı vardır, yalnızca OSAS'dan şüphelenilen yüksek riskli olgular çalışmaya alındığı için, sonuçlar genel popülasyona dikkatle uygulanmalıdır ve çalışmamız kesitsel bir analiz olduğundan, hesaba katılmamış, kafa karışıııcı faktörlerin yanlı sonuçlara neden olabileceği ihtimali vardır.

Çalışmamızın güçlü yanı ise, tüm hastalara, OSAS tanısının altın standardı olan PSG'nin yapılmasıdır.

Sonuç olarak; ülkemizde, altı bölgemizden, büyük bir hasta grubundaki çeşitli antropometrik ve obezite dağılım endekslerini, cinsiyetin etkisini hesaba katarak araştırdık. OSAS için yüksek risk altındaki hastaları tanımlayabilecek cut-off değerlerini bulmaya çalışık. Bu bağlamda ülke değerlerinin tespiti OSAS olasılığı olan hastaların belirlenmesi ve PSG için uyku merkezlerine yönlendirilmesi için önemli bir çalışma olduğunu düşünmekteyiz.

\section{ÇIKAR ÇATIŞMASI}

Yazarlar çıkar çatışması bildirmemişlerdir.

\section{YAZAR KATKISI}

Anafikir/Planlama: AU, ÖÖ, OK

Analiz/Yorum: ÖÖ, PM, AU

Veri sağlama: Tüm yazarlar

Yazım: ÖÖ, PM, AU

Gözden Geçirme ve Düzeltme: Tüm yazarlar

Onaylama: Tüm yazarlar

\section{KAYNAKLAR}

1. Young T, Palta M, Dempsey J, Skatrud J, Weber S, Badr S. The occurrence of sleep-disordered breathing among middle-aged adults. N Engl J Med 1993;328:1230-5.

2. Levy P, Bonsignore MR, Eckel J. Sleep, sleep-disordered breathing and metabolic consequences. Eur Respir J 2009;34(1):243-60.

3. Coughlin SR, Mawdsley L, Mugarza JA, Calverley PM, Wilding JP. Obstructive sleep apnoea is independently asso- ciated with an increased prevalence of metabolic syndrome. Eur Heart J 2004;25(9):735-41.

4. West $S D$, Nicoll DJ, Stradling JR. Prevalence of obstructive sleep apnea in men with type 2 diabetes. Thorax 2006;61(11):945-50.

5. Seicean S, Kirchner HL, Gottlieb DJ, Punjabi NM, Resnick $H$, Sanders $M$, et al. Sleep-disordered breathing and impaired glucose metabolism in normal-weight and overweight/obese individuals: the Sleep Heart Health Study. Diabetes Care 2008;31(5):1001-6.

6. Marin JM, Carrizo SJ, Vicente E, Agusti AG. Long-term cardiovascular outcomes in men with obstructive sleep apnoea-hypopnoea with or without treatment with continu- ous positive airway pressure: an observational study. Lancet 2005;365(9464):1046-53.

7. Doherty LS, Kiely IL, Swan V, McNicholas WT. Long-term effects of nasal continuous positive airway pressure therapy on cardiovascular outcomes in sleep apnea syndrome. Chest 2005;127(6):2076-84.

8. Peter $J H$, Koehler U, Grote L, Podszus T. Manifestations and consequences of obstructive sleep apnoea. Eur Respir J 1995;8(9):1572-83.

9. Young $T$, Finn L, Peppard PE, Szklo-Coxe M, Austin D, Nieto FJ, et al. Sleep disordered breathing and mortality: eighteen-year follow-up of the Wisconsin sleep cohort. Sleep 2008;31:1071-8.

10. Marshall NS, Wong KK, Liu PY, Cullen SR, Knuiman MW, Grunstein RR. Sleep apnea as an independent risk factor for all-cause mortality: the Busselton Health Study. Sleep 2008;31:1079-85.

11. Subramanian S, Jayaraman G, Majid H, Aguilar R, Surani $S$. Influence of gender and anthropometric measures on severity of obstructive sleep apnea. Sleep Breath 2012; 16(4):1091-5.

12. Onat A, Hergenc G, Yuksel H, Can G, Ayhan E, Kaya Z, et al. Neck circumference as a measure of central obesity: associations with metabolic syn-drome and obstructive sleep apnea syndrome beyond waist circumference. Clin Nutr 2009;28(1):46-51.

13. Soylu AC, Levent E, Sariman N, Yurtlu S, Alparslan S, Saygi A. Obstructive sleep apnea syndrome and anthropometric obesity indexes. Sleep Breath 2012;16(4):1151-8. 
14. Bouloukaki I, Kapsimalis F, Mermigkis C, Kryger M, Tzanakis N, Panagou P, et al. Prediction of obstructive sleep apnea syndrome in a large Greek population. Sleep Breath 2011;15(4):657-64.

15. Villaneuva $A T$, Buchanan $P R$, Yee BJ, Grunstein $R R$. Ethnicity and obstructive sleep apnoea. Sleep Med Rev 2005; 9:419-36.

16. Berry B, Brooks R, Gamaldo C, Harding S, Lloyd R, Marcus $C$, et al. The AASM manual for the scoring of sleep and associated events: rules, terminology and technical specifications [version 2.1] Darien, IL: American Acedemy of Sleep Medicine, 2014.

17. Chung F, Subramanyam R, Liao P, Sasaki E, Shapiro C, Sun $Y$. High STOP-Bang score indicates a high probability of obstructive sleep apnoea. Br J Anaesth 2012;108:768-75.

18. Acar HV, Kaya A, Yücel F, et al. Validation of the STOPBang questionnaire: an obstructive sleep apnoea screening tool in Turkish population. Turk I Anaesthesiol Reanim 2013;41:115-20.

19. Izci B, Ardic S, Firat H, Sahin A, Altinors M, Karacan I. Reliability and validity studies of the Turkish version of the Epworth Sleepiness Scale. Sleep Breath 2008;12:161-8.

20. Schwartz AR, Patil SP, Laffan AM, Polotsky V, Schneider H, Smith PL. Obesity and obstructive sleep apnea: pathogenic mechanisms and therapeutic approaches. Proc Am Thorac Soc 2008;5:185-92.

21. James WP. The epidemiology of obesity: the size of the problem. J Intern Med 2008;263:336-52.

22. Kagawa $M$, Binns CB, Hills AP. Body composition and anthropometry in Japanese and Australian Caucasian males and Japanese females. Asia Pac J Clin Nutr 2007; 16:31-6

23. Zhou JY, Ge H, Zhu MF, Wang LJ, Chen L, Tan YZ. Neck circumference as an independent predictive contributor to cardio-metabolic syndrome. Cardiovasc Diabetol $2013 ; 12: 76$.

24. Deegan PC, McNicholas WT. Predictive value of clinical features for the obstructive sleep apnoea syndrome. Eur Respir J 1996;9(1):117-24.

25. Chaves CM Jr, Teles MP, de Bruin PFC, de Bruin VMS, Gurgel ML, Rossi RRP, et al. Assessment of the craniofacial and cervical parameters using standardized photography in individuals with obstructive sleep apnea. Int Arch Med 2015;8:173.

26. Han TS, Oh MK, Kim SM, Yang HJ, Lee BS, Park SY, et al. Relationship between neck length, sleep, and cardiovascular risk factors. Korean J Fam Med 2015;36:10-21.

27. Cizza G, de Jonge L, Piaggi P, Mattingly $M$, Zhao X, Lucassen $E$, et al. Neck circumference is a predictor of metabolic syndrome and obstructive sleep apnea in shortsleeping obese men and women. Metab Syndr Relat Disord 2014; 12:231-41.
28. Davidson TM, Patel MR. Waist circumference and sleep disordered breathing. Laryngoscope 2008;118:339-47.

29. Executive Summary of The Third Report of The National Cholesterol Education Program (NCEP) Expert Panel on Detection, Evaluation, and Treatment of High Blood Cholesterol in Adults (Adult Treatment Panel III). JAMA 2001;285:2486-97.

30. Lee RW, Vasudavan S, Hui DS, Prvan T, Petocz P, Darendeliler MA, et al. Differences in craniofacial structures and obesity in Caucasian and Chinese patients with obstructive sleep apnea. Sleep 2010;33:1075-80.

31. Obesity: preventing and managing the global epidemic. Report of a WHO consultation. World Health Organ Tech Resp Ser 2000;894:1-253.

32. WHO Expert Consultation. Appropriate body-mass index for Asian populations and its implications for policy and intervention strategies. Lancet 2004;363:157-63.

33. Young $T$, Finn $L$, Austin D, Peterson A. Menopausal status and sleep-disordered breathing in the Wisconsin Sleep Cohort Study. Am J Respir Crit Care Med 2003;167:11815 .

34. Popovic RM, White DP. Influence of gender on waking genioglossal electromyogram and upper airway resistance. Am J Respir Crit Care Med 1995;152(2):725-31.

35. Pillar G, Malhotra A, Fogel R, Beauregard J, Schnall R, White DP. Airway mechanics and ventilation in response to resistive loading during sleep: influence of gender. Am J Respir Crit Care Med 2000;162(5):1627-32.

36. Trinder J, Kay A, Kleiman J, Dunai J. Gender differences in airway resistance during sleep. I Appl Physiol 1997;83(6): 1986-97.

37. White DP, Lombard RM, Cadieux RJ, Zwillich CW. Pharyngeal resistance in normal humans: influence of gender, age, and obesity. I Appl Physiol 1985;58(2):36571.

38. Rowley JA, Zhou X, Vergine I, Shkoukani MA, Badr MS. Influence of gender on upper airway mechanics: upper airway resistance and Pcrit.JApp/Physiol 2001;91(5):224854.

39. Kapsimalis F, Kryger MH. Gender and obstructive sleep apnea syndrome, part 2: mechanisms. Sleep 2002;25(5):499-506.

40. Martinez-Rivera C, Abad J, Fiz JA, Rios J, Morera J. Usefulness of truncal obesity indices as predictive factors for obstructive sleep apnea syndrome. Obesity 2008; 16(1):113-8. 